\title{
CYTOPLASMIC EFFECTS ON PLANT WEIGHT IN CROSSES BETWEEN FLAX GENOTYPES AND GENOTROPHS
}

\author{
H. TYSON \\ Biology Department, McGill University, Montreal, Quebec, Canada
}

Received 1.vi.72

\section{Summary}

\begin{abstract}
Crosses were made between two flax genotrophs, $\mathrm{L}$ and $\mathrm{S}$, and two other flax genotypes. With a given pair of parents and their reciprocal $F_{1}$ hybrids, crosses were made in all ways to generate 16 different progenies. Progeny means for total plant fresh weight were examined. Cytoplasmic effects were detected in these progeny. No reciprocal $F_{1}$ differences were found; cytoplasmic effects were seen as differences between the progeny of the one compared to the other $\mathrm{F}_{1}$ hybrid. Genetic and cytoplasmic effects were estimated by weighted least squares procedures. A depressant cytoplasmic effect was transmitted through the male gametes of $S$, while a positive effect was passed through the female gametes of $\mathrm{L}$.
\end{abstract}

\section{Introduction}

Hrahly inbred genotypes have been extensively examined in the context of crosses between two parents yielding various progeny generations. This basic situation has been exploited to assess the value of models of gene action in the partitioning of variability for quantitative characters.

Additional information is, however, retrievable from crosses in all combinations between two parents and their reciprocal $F_{1}$ hybrids. Such an arrangement, which provides parental $\mathrm{F}_{1}, \mathrm{~F}_{2}$ and backcross generations, including all reciprocals, has been used by Barnes (1968) in an analysis of the genetic system controlling yield in Drosophila melanogaster. Variation amongst generation means was summarised by fitting models through a weighted least-squares procedure, and testing these models for adequacy by $\chi^{2}$. Analysis of variance with all 16 progenies permitted tests for reciprocal differences in the $\mathrm{F}_{1}, \mathrm{~F}_{2}$ and backcross generations.

The same arrangement of crosses in all combinations between two parents and their reciprocal $F_{1}$ hybrids was used in the study reported here. Progenies from five flax crosses were examined for maternal and cytoplasmic effects. Parents comprised two genotypes derived through selection procedures, and two genotrophs, which had resulted from environmentally induced heritable changes in a single genotype (Durrant, 1962a, $b, 1971$ ).

Evans, Durrant and Rees (1966) established that in apical meristematic tissue there was a difference between the two genotrophs $\mathrm{L}$ and $\mathrm{S}$ in amount of DNA per cell nucleus; L contained 16 per cent. more DNA on this basis than S. Further work by Evans $(1968 a, b)$ indicated that these nuclear changes in the genotrophs were accompanied by changes in the structure and organisation of the chromosomes.

In terms of mean progeny performance for plant weight at maturity, a diallel cross between genotypes and genotrophs (Durrant and Tyson, 1964) demonstrated that the genotrophs $\mathrm{L}$ and $\mathrm{S}$ behaved as distinct 
genetic types. Analysis of $\mathrm{F}_{2}$ reciprocal differences in this diallel by Durrant (1965) indicated that there were, additionally, cytoplasmic differences between $\mathrm{L}$ and $\mathrm{S}$.

The inclusion of all possible reciprocals in the crosses described here provided another format for the detection of cytoplasmic effects in the genotrophs $\mathrm{L}$ and $\mathrm{S}$.

\section{Materials and methods}

The two genotypes were the cultivars Mandarin (M) and Dakota (D); the two genotrophs $(\mathrm{L}=$ large, $\mathrm{S}=$ small) had been produced by fertiliser treatment (NPK or NK) of one generation of a single genotype (Stormont Cirrus). The production and testing of these genotrophs has been documented by Durrant (1962); parent plants used in the present study were the third-generation progeny of the original plants which received the NK and NPK treatments. These genotypes and genotrophs set seed by complete self-pollination; there was no evidence of any outcrossing.

Parent genotypes and genotrophs were arranged in five sets of crosses:

\section{Set 1: $\quad$ Set 2: $\quad$ Set 3: Set 4: Set 5:}

Parents: M, S Parents: M, L Parents: D, S Parents: D, L Parents: S, L.

The $(5 \times 16)=80$ progenies from the five sets of crosses were randomised within each of the three replicates of a randomised block design, thus allowing comparisons within and between sets. Each progeny in a given set was represented in each replicate by one row of five plants, with the exception that for $\mathrm{P}_{1}, \mathrm{P}_{2}$ and the two $\mathrm{F}_{2}$ 's stemming from crossing within each of the two reciprocal $F_{1}$,s there were two rows per replicate. Individual plants were weighed fresh after cutting at ground level 120 days from germination. The maximum number of plants in each set was 300 ; losses were minor, ranging from 3 per cent. in set 2 to 9 per cent. in set 4 . Mean plant weights for each progeny in each set of crosses are shown in table 1. For each set in this table, parents and $F_{1}$ 's from which the 16 progenies were generated are listed down the left-hand margin (females) and along the upper margin (males); they are additionally symbolised as 1 to 4 . Each of the 16 progenies in a set of crosses may then be conveniently referred to in these terms, so that $\mathrm{P}_{1}$ is $11, \mathrm{P}_{2}$ is $44, \mathrm{~F}_{1}\left(\mathrm{P}_{1} \times \mathrm{P}_{2}\right)$ is $14, \mathrm{~F}_{1}\left(\mathrm{P}_{2} \times \mathrm{P}_{1}\right)$ is 41 ,

$$
\mathrm{F}_{2}\left[\mathrm{~F}_{1}\left(\mathrm{P}_{1} \times \mathrm{P}_{2}\right) \times \mathrm{F}_{1}\left(\mathrm{P}_{2} \times \mathrm{P}_{1}\right)\right]
$$

is 23 , and so on. The first number thus indicates the female, the second the male; the combination of the two indicates the resultant progeny. This notation is used in what follows for more concise descriptions of the 16 progenies.

The choice of scale for the individual measurements attempted to satisfy the triple requirements of independence between within-row means and standard deviations for non-segregating generations, homogeneity of progeny by replicate interaction mean squares and of error mean squares over sets for analyses of variance of individual sets, and, finally, absence of nonallelic interaction in comparisons of observed and expected $\mathrm{F}_{2}$ and backcross generation means. Comparisons of observed with expected backcross means were made using generations with common maternal (or paternal) parents, as suggested by Mather and Jinks (1971). This also applied to $\mathrm{F}_{2}$ comparisons. 
TABLE 1

Total plant weight $(g)$. Mean values for each progeny in each set

\begin{tabular}{|c|c|c|c|c|c|c|}
\hline & & $1=M$ & $2=\mathrm{F}_{1}(\mathrm{M} \times \mathrm{S})$ & $3=F_{1}(S \times M)$ & $4=S$ & Means \\
\hline SET 1 & $\left\{\begin{array}{l}1=\mathrm{M} \\
2=\mathrm{F}_{1}(\mathrm{M} \times \mathrm{S}) \\
3=\mathrm{F}_{1}(\mathrm{~S} \times \mathrm{M}) \\
4=\mathrm{S}\end{array}\right.$ & $\begin{array}{l}46 \cdot 9 \\
66 \cdot 6 \\
44 \cdot 3 \\
64 \cdot 4\end{array}$ & $\begin{array}{l}40 \cdot 8 \\
50 \cdot 3 \\
63 \cdot 1 \\
60 \cdot 9\end{array}$ & $\begin{array}{l}65 \cdot 5 \\
61 \cdot 1 \\
47 \cdot 5 \\
38 \cdot 4\end{array}$ & $\begin{array}{l}58 \cdot 3 \\
40 \cdot 0 \\
38 \cdot 3 \\
40 \cdot 4\end{array}$ & $\begin{array}{l}52 \cdot 9 \\
54 \cdot 5 \\
48 \cdot 3 \\
51 \cdot 0\end{array}$ \\
\hline & Means & $55 \cdot 6$ & $53 \cdot 8$ & $53 \cdot 1$ & $44 \cdot 3$ & \\
\hline & & $I=M$ & $2=F_{1}(M \times L)$ & $3=F_{1}(L \times M)$ & $4=\mathrm{L}$ & Means \\
\hline Set 2 & $\left\{\begin{array}{l}1=\mathrm{M} \\
2=\mathrm{F}_{1}(\mathrm{M} \times \mathrm{L}) \\
3=\mathrm{F}_{1}(\mathrm{~L} \times \mathrm{M}) \\
4=\mathrm{L}\end{array}\right.$ & $\begin{array}{l}50 \cdot 3 \\
76 \cdot 3 \\
87 \cdot 7 \\
80 \cdot 6\end{array}$ & $\begin{array}{r}61 \cdot 5 \\
85 \cdot 4 \\
104 \cdot 4 \\
117 \cdot 1\end{array}$ & $\begin{array}{r}76 \cdot 7 \\
92 \cdot 0 \\
85 \cdot 1 \\
122 \cdot 8\end{array}$ & $\begin{array}{r}84 \cdot 1 \\
103 \cdot 7 \\
115 \cdot 5 \\
131 \cdot 9\end{array}$ & $\begin{array}{r}68 \cdot 2 \\
89 \cdot 4 \\
98 \cdot 2 \\
113 \cdot 1\end{array}$ \\
\hline & Means & $73 \cdot 7$ & $92 \cdot 1$ & $94 \cdot 2$ & $108 \cdot 8$ & \\
\hline & & $1=\mathrm{D}$ & $2=F_{1}(D \times S)$ & $3=F_{1}(S \times D)$ & $4=S$ & Means \\
\hline SET 3 & $\left\{\begin{array}{l}1=\mathrm{D} \\
2=\mathrm{F}_{1}(\mathrm{D} \times \mathrm{S}) \\
3=\mathrm{F}_{1}(\mathrm{~S} \times \mathrm{D}) \\
4=\mathrm{S}\end{array}\right.$ & $\begin{array}{r}123 \cdot 0 \\
85 \cdot 1 \\
130 \cdot 2 \\
138 \cdot 2\end{array}$ & $\begin{array}{r}127 \cdot 8 \\
77 \cdot 5 \\
97 \cdot 7 \\
65 \cdot 9\end{array}$ & $\begin{array}{l}86 \cdot 2 \\
67 \cdot 8 \\
79 \cdot 7 \\
51 \cdot 5\end{array}$ & $\begin{array}{r}117 \cdot 0 \\
84.5 \\
71.9 \\
50 \cdot 3\end{array}$ & $\begin{array}{r}113.5 \\
78 \cdot 7 \\
94.9 \\
76.5\end{array}$ \\
\hline & Means & $119 \cdot 1$ & $92 \cdot 2$ & $71 \cdot 3$ & $80 \cdot 9$ & \\
\hline & & $1=D$ & $2=F_{1}(D \times L)$ & $3=F_{1}(L \times D)$ & $4=\mathrm{L}$ & Means \\
\hline SET 4 & $\left\{\begin{array}{l}1=\mathrm{D} \\
2=\mathrm{F}_{1}(\mathrm{D} \times \mathrm{L}) \\
3=\mathrm{F}_{1}(\mathrm{~L} \times \mathrm{D}) \\
4=\mathrm{L}\end{array}\right.$ & $\begin{array}{l}130 \cdot 3 \\
106 \cdot 6 \\
121 \cdot 0 \\
187 \cdot 8\end{array}$ & $\begin{array}{l}144 \cdot 1 \\
132 \cdot 3 \\
147 \cdot 7 \\
154 \cdot 8\end{array}$ & $\begin{array}{l}158 \cdot 1 \\
100 \cdot 0 \\
157 \cdot 7 \\
152 \cdot 8\end{array}$ & $\begin{array}{l}162 \cdot 2 \\
118 \cdot 7 \\
147 \cdot 7 \\
106 \cdot 0\end{array}$ & $\begin{array}{l}148 \cdot 7 \\
114 \cdot 4 \\
143 \cdot 5 \\
150 \cdot 4\end{array}$ \\
\hline & Means & $136 \cdot 4$ & $144 \cdot 7$ & $142 \cdot 2$ & $133 \cdot 7$ & \\
\hline & & $1=S$ & $2=\mathrm{F}_{1}(\mathrm{~S} \times \mathrm{L})$ & $3=F_{1}(L \times S)$ & $4=\mathrm{L}$ & Means \\
\hline SET 5 & $\left\{\begin{array}{l}1=\mathrm{S} \\
2=\mathrm{F}_{1}(\mathrm{~S} \times \mathrm{L}) \\
3=\mathrm{F}_{1}(\mathrm{~L} \times \mathrm{S}) \\
4=\mathrm{L}\end{array}\right.$ & $\begin{array}{r}33 \cdot 7 \\
63 \cdot 4 \\
86 \cdot 2 \\
103 \cdot 2\end{array}$ & $\begin{array}{r}63 \cdot 1 \\
81 \cdot 2 \\
65 \cdot 3 \\
116 \cdot 9\end{array}$ & $\begin{array}{l}62 \cdot 1 \\
66 \cdot 8 \\
81 \cdot 5 \\
76 \cdot 0\end{array}$ & $\begin{array}{r}92 \cdot 3 \\
71 \cdot 2 \\
124 \cdot 6 \\
127 \cdot 0\end{array}$ & $\begin{array}{r}62 \cdot 8 \\
70 \cdot 7 \\
89 \cdot 4 \\
105 \cdot 8\end{array}$ \\
\hline & Means & $71 \cdot 6$ & $81 \cdot 6$ & $71 \cdot 6$ & $103 \cdot 8$ & \\
\hline
\end{tabular}

Transformation to a log scale eliminated the significant correlation between within-row means and standard deviations, and the significant heterogeneity amongst the five interaction mean squares. Significant, although reduced, heterogeneity remained, however, amongst the five error mean squares of the analyses of variance. In backcrosses to parent 2, where this parent was common in the $F_{1}$ 's and backcrosses $\left(B_{2}\right.$ 's), a significant departure was detected for set 3 . The log transformation was thus not entirely satisfactory. Nevertheless, analyses of means were of primary interest here, and a uniform transformation of all data in all sets to a log scale was made, therefore, as an acceptable solution to scaling problems.

In a given set all individual $\log _{n}$ plant weights were used initially in an analysis of variance. Unequal sub-class numbers were handled by an 
appropriate least-squares procedure, and orthogonal comparisons made among the estimated means of progenies; these comparisons are detailed in table 2. The interaction sum of squares in a set was broken down to extract the heterogeneity of each progeny comparison in table 2 over replicates. Such heterogeneity mean squares were tested against the residual within-row variability of the set as the error term. Where significant, a heterogeneity mean square was used for testing the corresponding progeny comparison over replicates. Where not significant, the corresponding progeny comparison was tested against the residual within-row variability as a more sensitive, alternative error. Results of the analyses are shown in table 3.

TABLE 2

Orthogonal comparisons among progenies; cytoplasmic effects within segregating generations

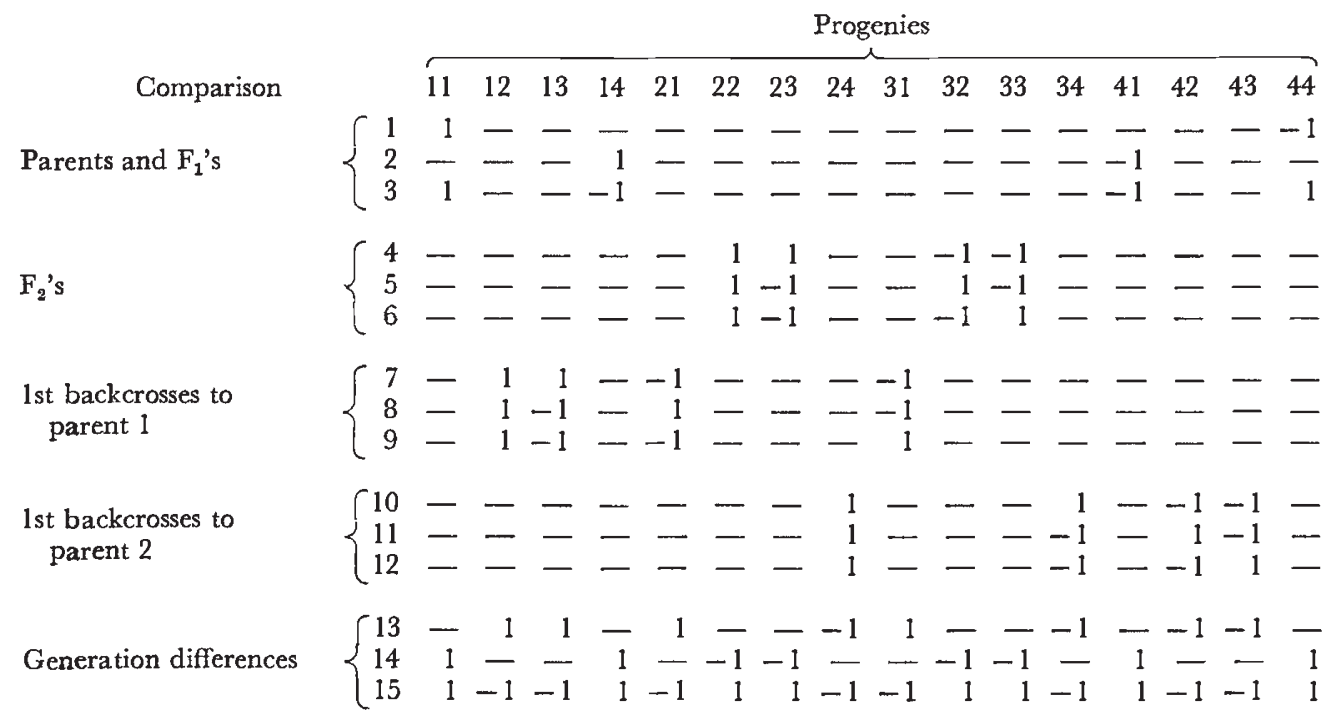

Using progeny means derived from $\log _{n}$ data in each replicate, sets 1 to 4 were combined into a single analysis in which the sum of all first- and second-order interactions of progenies and sets with replicates, with 126 degrees of freedom, supplied the error term. The 15 comparisons made amongst progenies (table 2) were combined with three comparisons amongst the four sets, namely, the effects of genotypes summed over both genotrophs, the effects of genotrophs summed over both genotypes, and the interaction between these effects, as shown below:

\begin{tabular}{crrrr} 
Comparison & \multicolumn{4}{c}{ Set } \\
\cline { 2 - 4 } 1 & 1 & 2 & 3 & 4 \\
2 & 1 & -1 & -1 & -1 \\
3 & 1 & -1 & -1 & -1 \\
& 1 & & 1 & 1
\end{tabular}

The significant results from this analysis are summarised in table 4 . 
TABLE 3

Analyses of variance of $\log _{n}$ values. Comparisons among progenies as detailed in table 2. F ratios shown here

\begin{tabular}{|c|c|c|c|c|c|c|}
\hline \multirow{2}{*}{\multicolumn{2}{|c|}{ Comparison }} & & & & & \\
\hline & & 1 & 2 & 3 & 4 & 5 \\
\hline Parents and $F_{\mathbf{x}}$ 's & $\left\{\begin{array}{l}1 \\
2 \\
3\end{array}\right.$ & $\begin{array}{l}<1 \\
<1 \\
16.93 * *\end{array}$ & $\begin{array}{l}12 \cdot 10^{* *} \\
<1 \\
<1\end{array}$ & $\begin{array}{l}84 \cdot 07 * * \\
<1 \\
32 \cdot 32 * *\end{array}$ & $\begin{array}{c}8 \cdot 35 * * \\
1 \cdot 23 \\
32 \cdot 61 * *\end{array}$ & $\begin{array}{l}150 \cdot 36 * * \\
<1 \\
1 \cdot 61\end{array}$ \\
\hline$F_{2}$ 's & $\left\{\begin{array}{l}4 \\
5 \\
6\end{array}\right.$ & $\begin{aligned} &<1 \\
&<1 \\
& 8 \cdot 22 * *\end{aligned}$ & $\begin{array}{l}<1 \\
<1 \\
1 \cdot 10\end{array}$ & $\begin{aligned} & 4 \cdot 41 * \\
& 6 \cdot 73^{*} \\
< & 1\end{aligned}$ & $\begin{aligned} & 2 \cdot 26 \\
& 3 \cdot 48 \\
< & 1\end{aligned}$ & $\begin{array}{l}<1 \\
<1 \\
10 \cdot 04 * *\end{array}$ \\
\hline 1st backcrosses to parent 1 & $\left\{\begin{array}{l}7 \\
8 \\
9\end{array}\right.$ & $\begin{array}{l}<1 \\
<1 \\
25 \cdot 0 * *\end{array}$ & $\begin{array}{l} \\
\quad 5 \cdot 81 * \\
<1 \\
<1\end{array}$ & $\begin{array}{l}<1 \\
<1 \\
3.47\end{array}$ & $\begin{aligned} & 9 \cdot 11 * * \\
&< 1 \\
&<1\end{aligned}$ & $\begin{array}{l}<1 \\
<1 \\
<1\end{array}$ \\
\hline 1st backcrosses to parent 2 & $\left\{\begin{array}{l}10 \\
11 \\
12\end{array}\right.$ & $\begin{array}{l}5 \cdot 98 * \\
6 \cdot 79 * * \\
7 \cdot 81 * *\end{array}$ & $\begin{array}{l}1.43 \\
<1.07\end{array}$ & $\begin{aligned} & 1.25 \\
& 3.98^{*} \\
< & 1\end{aligned}$ & $\begin{aligned} & 3 \cdot 77 \\
&< 1 \\
& 2 \cdot 73\end{aligned}$ & $\begin{array}{l}<1 \\
<1 \\
6.87\end{array}$ \\
\hline Generation differences & $\left\{\begin{array}{l}13 \\
14 \\
15\end{array}\right.$ & $\begin{array}{l}12 \cdot 83 * * \\
<1 \\
7 \cdot 03 * *\end{array}$ & $\begin{array}{l}46 \cdot 08 * * \\
2 \cdot 49 \\
4.57 *\end{array}$ & $\begin{array}{l}31 \cdot 25^{* *} \\
14 \cdot 51 * * \\
<1\end{array}$ & $\begin{array}{l}<1 \\
\quad 3 \cdot 04 \\
<1\end{array}$ & $\begin{array}{l}22 \cdot 74^{* *} \\
6 \cdot 03^{*} \\
<1\end{array}$ \\
\hline
\end{tabular}

* Significant at probability 0.05 ; ** Significant at probability 0.01 .

TABLE 4

Significant contributions to the progeny by set interaction, sets 1 to 4

(a) Genotroph differences $=$ sets $(1+3-2-4)$

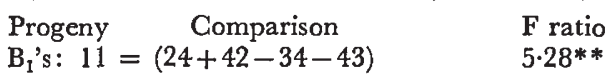

(b) Genotype differences $=$ sets $(1+2-3-4)$

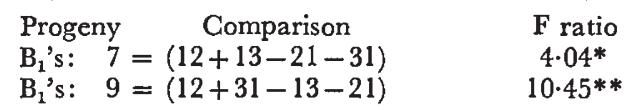

* Significant at probability $0.01 ; * *$ Significant at probability 0.05 .

To account for variation between and within generations (amongst progenies) in a set, models were fitted by a weighted least-squares procedure and tested for adequacy of fit by $\chi^{2}$. These are elaborated in section $3(\mathrm{~A})$

\section{RESUlts}

(A) Analyses of variance on individual sets

The results from each analysis are shown in table 3. Both main factors were tested against their interaction, while the interaction was compared with residual within-row variability (error); interactions were significant in each set.

Orthogonal comparisons amongst progenies are detailed in table 2. These examined $\left(\overline{\mathrm{P}}_{1}-\overline{\mathrm{P}}_{2}\right),\left(\overline{\mathrm{F}}_{1}-\overline{\mathrm{F}}_{1}\right),\left(2 \overline{\mathrm{F}}_{1}-\overline{\mathrm{P}}_{1}-\overline{\mathrm{P}}_{2}\right),\left(\overline{\mathrm{B}}_{1}-\overline{\mathrm{B}}_{2}\right),\left(2 \overline{\mathrm{F}}_{1}+\overline{\mathrm{P}}_{1}+\overline{\mathrm{P}}_{2}-4 \overline{\mathrm{F}}_{2}\right)$ and $\left(2 \overline{\mathrm{F}}_{1}+\overline{\mathrm{P}}_{1}+\overline{\mathrm{P}}_{2}+4 \mathrm{~F}_{2}-4 \overline{\mathrm{B}}_{1}-4 \overline{\mathrm{B}}_{2}\right)$ differences in comparisons $1,2,3,13$, 14 and 15 respectively. Comparisons 4 to 12 examined maternal and cytoplasmic effects in each of the segregating generations. For the four $\mathrm{F}_{2}$ 's $(22,23,32,33)$, effects stemming from the use of the two reciprocal $F_{1}$ 's 
either as female or as male parents were examined in comparisons 4 and 5, while the interaction between male and female effects was tested by 6 . For the four $\mathrm{B}_{1}$ 's, effects of $\mathrm{P}_{1}$ as a female versus a male parent were tested by comparison 7 , while 8 examined effects of the alternative $F_{1}$ parents. Comparison 9 checked the difference due to alternative $F_{1}$ 's as females versus male parents. Comparisons 10,11 and 12 completed identical tests for the four $\mathrm{B}_{2}$ 's.

For set 3, significant cytoplasmic effects were transmitted through male and female gametes in the $\mathrm{F}_{2}$. Interaction between male and female transmitted effects in the $F_{2}$ was detected for sets 1 and 5 . Reference to table 1 indicates that this interaction stemmed from reversal, complete for set 5 , in $\mathrm{F}_{2}$ effects.

Such cytoplasmic effects stemming from the alternative $\mathrm{F}_{1}$ 's were not found in the $B_{1}$ generation, but did occur in the $B_{2}$ for sets 1 and 3 . There was evidence of a maternal influence of $P_{1}$ in sets 2 and 4 for $B_{1}$, and of $P_{2}$ in set 1 for $B_{2}$. For set 1 in both $B_{1}$ and $B_{2}$ there was a significant difference between the effects of the alternative $F_{1}$ 's as female compared to male parents.

Thus, while there were no $F_{1}$ reciprocal differences in any of the five sets, there were significant cytoplasmic effects. Their occurrence introduced the examination of cytoplasmic differences between the genotrophs, or between the genotypes.

\section{(B) Combined analysis of sets 1,2,3 and 4}

Of the three relevant comparisons amongst these sets, the first two allowed the differences between genotypes over genotrophs, and between genotrophs over genotypes, in respect of the progeny comparisons (table 2) to be extracted. The results of this breakdown of the progeny by set interaction, with 45 degrees of freedom, are summarised in table 4 . The summary concerns only comparisons 4 to 12 amongst progenies, and 1 and 2 amongst sets, to centre attention on the differences between genotrophs' and genotypes' cytoplasmic effects.

The breakdown revealed three significant sums of squares. For the contrast between genotrophs, that is (set $1+$ set 3 -set 2 -set 4 ), there was a difference in $B_{2}$ between the effects of alternative $F_{1}$ 's (progeny comparison 11) dependent on $\mathrm{L}$ versus $\mathrm{S}$. With $\mathrm{S}$ as the second parent in this backcross, the size of the cytoplasmic effect of the alternative $F_{1}$ 's was much larger than when $\mathrm{L}$ was the second parent. For both $\mathrm{S}$ and $\mathrm{L}$, their behaviour in comparison 11 was thus summed over their individual crosses with the two other genotypes, to supply the contrast in this combined analysis.

In the contrast between genotypes, two significant mean squares were detected in $\mathrm{B}_{1}$. Reference to the progeny comparisons (table 2) shows that there was a difference between the maternal effect of $P_{1}$ (the genotype parent) dependent on whether $M$ or $D$ was used; the size of this effect was much larger for $D$. There was also a difference between the two genotypes in respect of the alternative $F_{1}$ effects as male or female parents in $B_{1}$.

Analyses of variance of individual and of combined sets indicated the existence of cytoplasmic effects, and of a cytoplasmic difference between $\mathrm{L}$ and $\mathrm{S}$. These results were derived from comparisons which checked segregating generations separately for cytoplasmic effects. The problem of estimation of genetic and cytoplasmic parameters for the five sets of crosses followed from these analyses. 


\section{(C) Models}

In searching for a model which adequately summarised the data and, ideally, permitted extrapolation to related situations, essentially two approaches existed. On the one hand, parameters could be included in a model to account for known biological processes. On the other hand, parameters might solely specify effects stemming from the measurements' classification in, say, a data matrix, or $4 \times 4$ table of results for any one set. In this latter approach, some of the parameters used, for example those for row and column effects in such a data matrix, could then have recognisable biological meaning in the context of the experiment.

Mather and Jinks (1971) have described models, applicable to a set of the crosses made here, with parameters estimating additive $(d)$ and dominance $(h)$ gene effects as well as maternal (or paternal) contributions of homozygotes and heterozygotes. A model with the five parameters $m$ (= mean), $d, h, d m$ and $h m$ may be fitted to the nine generation means obtained by treating the $F_{1}$ reciprocals separately, and by distinguishing backcrosses with $\mathrm{P}_{1}$ or $\mathrm{P}_{2}$ as a female parent from those with the $\mathrm{F}_{1}$ as a female. The base for this model is the three parameter model for the estimation of additive and dominance gene effects; the expectations for six generations means that provide $m, d$ and $h$ are:

\begin{tabular}{cllllrr} 
& \multicolumn{6}{c}{ Generation } \\
\cline { 2 - 4 } & $\overline{\mathrm{P}}_{1}$ & $\overline{\mathrm{B}}_{1}$ & $\overline{\mathrm{F}}_{1}$ & $\overline{\mathrm{F}}_{2}$ & $\overline{\mathrm{B}}_{2}$ & $\overline{\mathrm{P}}_{2}$ \\
$m$ & 1 & 1 & 1 & 1 & 1 & 1 \\
{$[d]$} & 1 & 0.5 & 0 & 0 & -0.5 & -1 \\
{$[h]$} & 0 & 0.5 & 1 & 0.5 & 0.5 & 0
\end{tabular}

This model exemplifies the first approach mentioned. The five parameter model estimating $m, d, h, d m$ and $h m$ was fitted to the nine generation means detailed above; this was carried out for each set by the weighted leastsquares procedure employed by Barnes (1968).

Estimates of cytoplasmic effects across segregating generations, in terms of comparisons among row and column means in a $4 \times 4$ data matrix, were also made through the group of orthogonal comparisons shown in table 5 . In so doing, cytoplasmic effects were examined in terms of differences between all progenies of the one compared to the other reciprocal $F_{1}$ hybrid. A difference between the means of rows 2 and 3 in a data matrix (comparison 4 , table 5) would reflect transmission of such effects by female gametes from the reciprocal $F_{1}$ 's; $F_{1}$ male gamete transmission would be seen as a column 3 difference (comparison 5). With the inclusion of a dummy variable to estimate the mean, and the selection of those parameters from this group required for specification of principal contributions to variation amongst progeny means, resultant models were fitted by weighted least-squares procedure. Fitting, using progeny means, was carried out in each of the five sets. Weights were reciprocals of variances of progeny means. In conjunction with the completely orthogonal columns of the design matrix of this type of model, the $\chi^{2}$ test of the residual sum of squares at each fitting in the sequential elimination of redundant comparisons permitted straightforward discrimination of those parameters adequately summarising the data. This represented the second approach to modelling. 
Both approaches were also combined, so that additive $(d)$ and dominance (h) gene effects as well as the mean could be estimated concurrently with cytoplasmic effects in terms of row and column effects in a data matrix. The expectations for progeny means are shown in table 6. Fitting of this

TABLE 5

Orthogonal comparisons among progenies; cytoplasmic effects across segregating generations

Progenies

Comparison

Parental effects

female

male

interaction

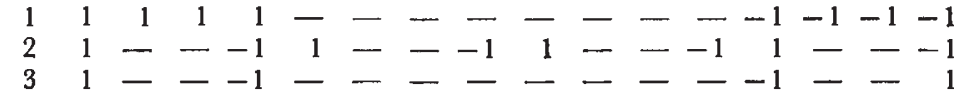

Cytoplasmic effects

female

male

interaction

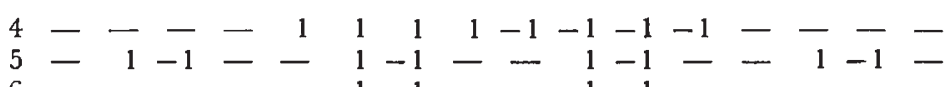

Parental-cytoplasmic interactions

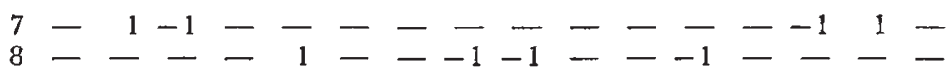

$\mathrm{F}_{1}$ effects

female

male

$\begin{array}{rrrrrrrrrrrrrrrrr}9 & 1 & 1 & 1 & 1 & -1 & -1 & -1 & -1 & -1 & -1 & -1 & -1 & 1 & 1 & 1 & 1 \\ 10 & 1 & -1 & -1 & 1 & 1 & -1 & -1 & 1 & 1 & -1 & -1 & 1 & 1 & -1 & -1 & 1\end{array}$

interaction

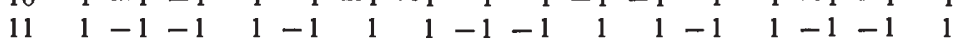

Parental-F interactions

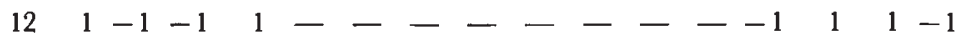

Cytoplasmic-F interactions

$\begin{array}{lllllllllllllll}12 & 1 & -1 & -1 & 1 & - & - & - & - & - & - & -1 & 1 & -1 \\ 13 & 1 & - & - & -1 & -1 & - & - & -1 & -1 & -1 & -1\end{array}$

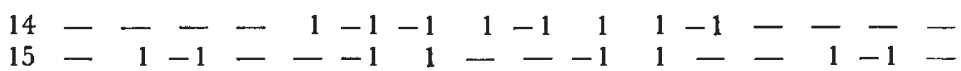

TABLE 6

Orthogonal comparisons among progenies; estimation of $d, h$, plus cytoplasmic effects across segregating generations

Progenies

Parameter

Additive gene effects, $[d] \quad 11 \quad 1 \quad \frac{1}{2} \quad \frac{1}{2}-\frac{1}{2}--\frac{1}{2} \quad \frac{1}{2}--\frac{1}{2}-\rightarrow^{\frac{1}{2}}-\frac{1}{2}-1$

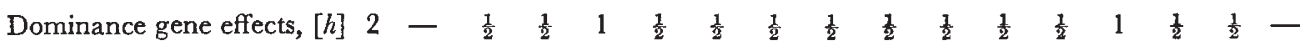

Comparisons:

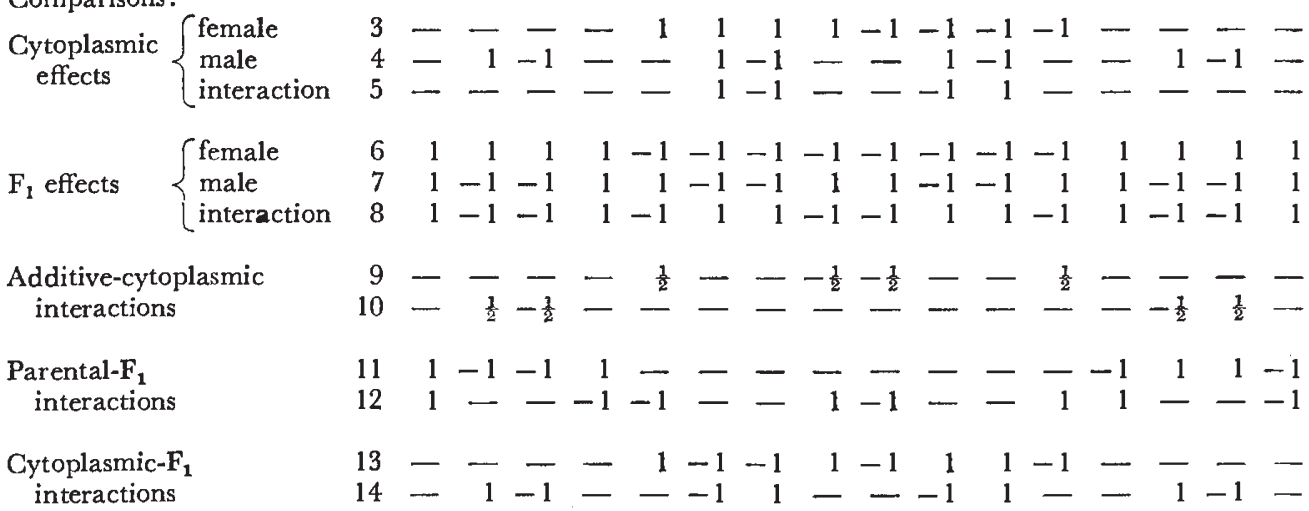


model in each set was carried out, as before, with a weighted least-squares procedure coupled with sequential elimination of redundant parameters on the basis of $\chi^{2}$ tests of residual sums of squares.

Fitting a genetical model with the five parameters $m, d, h, d m$ and $h m$ did not adequately summarise variation in generation means in any set. The variation among progeny means could, however, be adequately summarised in each of the five sets by either of the alternatives (tables 5,6); results from the use of the table 6 model are shown in table 7. For each set, the estimates represented the minimum group for prediction of progeny means.

TABLE 7

Estimates of parameters detailed in table 6 . Standard errors shown under each estimate

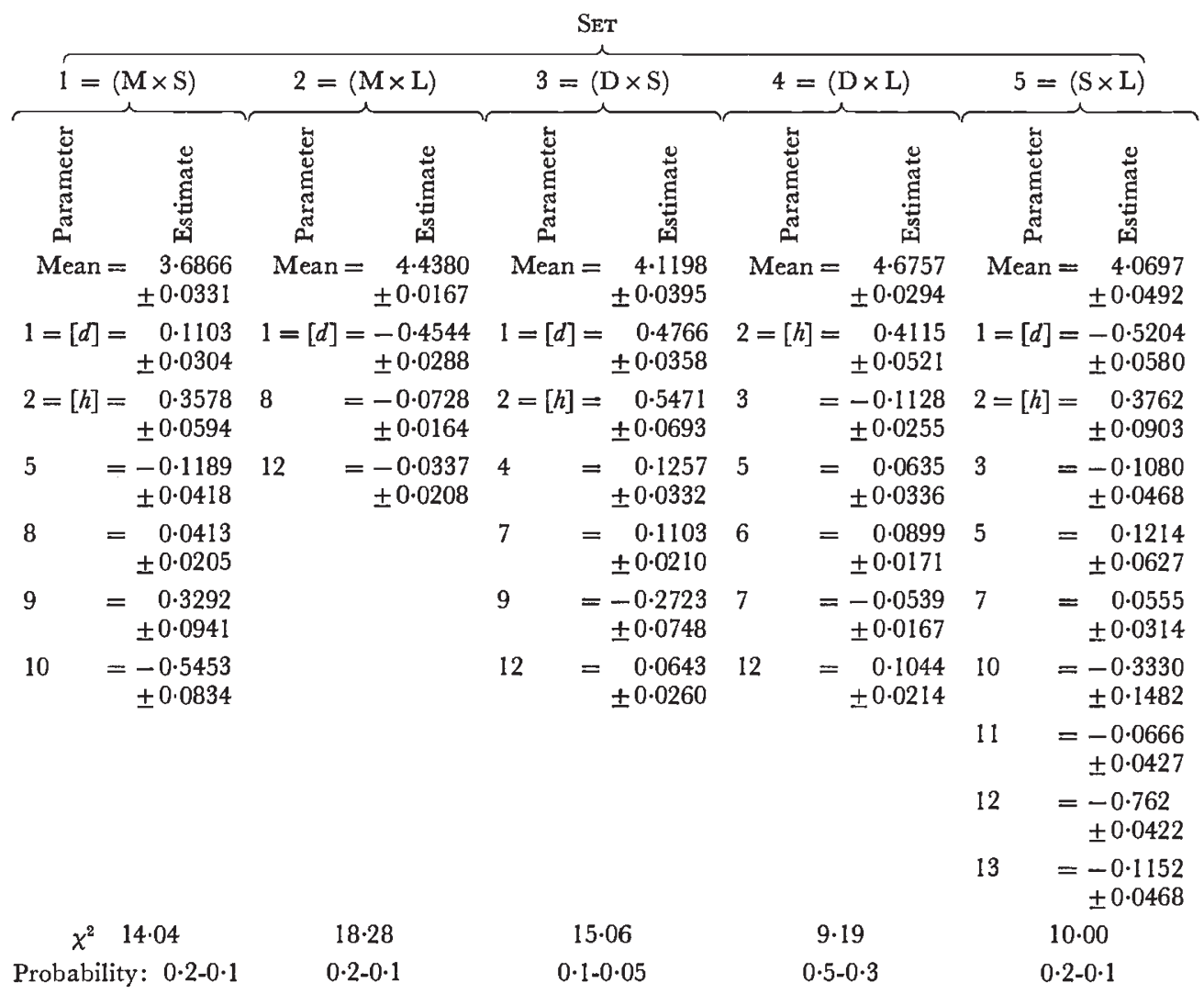

Comparison of results in table 7 indicated that in sets 3,4 and 5 there were detectable cytoplasmic effects across segregating generations. These stemmed from the reciprocal $F_{1}$ 's, where these were used as female parents (sets 4 and 5), or as male parents (set 3). Interaction between male and female cytoplasmic effects occurred in sets 1, 4 and 5; this was the interaction within $\mathrm{F}_{2}$ 's (comparison 6 , table 2). Additive gene effects were present in all but set 4, while dominance effects appeared in all but set 2. Barnes (1968) included a parameter $(f)$ to estimate the maternal effect associated with the $F_{1}$ in his study of maternal control of heterosis in Drosophila. An $F_{1}$ effect was examined in a similar fashion here through the comparisons $(6,7$, table 
6) of all progeny from both $\mathrm{F}_{1}$ 's with all those from both homozygous parents. Overall $F_{1}$ effects in a maternal direction were found in set 4 , with a paternal direction in sets 3,4 and 5 , and an interaction between these in sets 1 and 2. The remaining parameters variously required in the individual set models were concerned with interactions between these principal effects.

The assessment of cytoplasmic effects across segregating generations in combinations of the data for $S$ (sets $1+3$ ) and $L($ sets $2+4$ ) led to the final part of the investigation. Summation of corresponding progeny means has already been described in relation to the combined analysis of sets 1 to 4 and the examination of cytoplasmic differences between S and L. Averaging corresponding progeny means in sets 1 and 3, similarly sets 2 and 4, supplied two new sets of 16 means each to which the models detailed in tables 5 and 6 were fitted through the procedures outlined above. The appropriate weights were calculated from the within-plot sums of squares. Where $S S W(111)_{i j}$ represented a within-plot sum of squares for progeny 11 in set 1 , and $S S W(113)_{i j}$ a within-plot sum of squares for the corresponding progeny in set 3 , and where $D F(111)_{i j}$ and $D F(113)_{i j}$ represented the degrees of freedom pertaining to these $S S W$ 's, then the common variance, ${ }_{C 1}^{2}$, for all 11 individuals in sets 1 and 3 was obtained as:

$$
\begin{aligned}
{\left[\sum_{i} \sum_{j} S S W(111)_{i j}+\sum_{i} \sum_{j} S S W(113)_{i j}\right] / } \\
{\left[\sum_{i} \sum_{j} D F(111)_{i j}+\sum_{i} \sum_{j} D F(113)_{i j}\right]=s_{C 11}^{2} }
\end{aligned}
$$

with subscripts $i=1,2$ (no. of plots within replicates), and ${ }_{j}=1,3$ (no. of replicates). If $\mathcal{N}(111)$ and $\mathcal{N}(113)$ represented the total number of individuals for progeny type 11 in sets 1 and 3 respectively, the variance of the mean of these in the combined sets was:

$$
s_{C 11}^{2} /[\mathcal{N}(111)+\mathcal{N}(113)]=s \frac{2}{C 11} .
$$

The weight used for 11 in the combined sets was then $\left(s \frac{2}{C 11}\right)^{-1}$

The combination of sets 1 and 3 (or 2 and 4) allowed the average performance of $\mathrm{S}$ (or $\mathrm{L}$ ) against both $\mathrm{M}$ and $\mathrm{D}$ to be extracted in terms of table 5 or 6 parameters. The results are shown in table 8 .

In table 8, cytoplasmic effects across segregating generations were again the feature of immediate interest. It can be seen that there was a significant depressant cytoplasmic effect transmitted through the male gametes in the case of $\mathrm{S}$, while for $\mathrm{L}$ there was a significant positive cytoplasmic effect transmitted through the female gametes. This was found using either model.

The parameter estimates extracted for $\mathrm{S}$ and $\mathrm{L}$ were then used to predict the performance in the cross between $S$ and L (set 5). The group of coefficients in table 5 was the design matrix, symbolised, after transposition, by $X$. Positioning parameters for $\mathrm{S}$ in a column vector of dimensions 15 by 1 , with redundant $\mathrm{S}$ parameters indicated by zeros, gave a vector, $b_{s}$. A corresponding process supplied $b_{1}$. Prediction of progeny type means in set 
5 through $X b$ required slight modification of $X$ here, since there were two separate vectors of estimates $\left(b_{s}\right.$ and $\left.b_{1}\right)$; replacement firstly of negative coefficients in $X$ by zeros to give $X_{s}$, and secondly positive coefficients by zeros to give $X_{1}$, with all remaining negative coefficients' signs becoming positive, permitted the predictions to be found from:

$$
m+X_{s} b_{8}+X_{1} b_{1}=p,
$$

where $m$ was a column vector containing the observed mean of the 16 progeny means in set 5 , and $p$ was the resulting vector of predicted progeny means.

TABLE 8

Estimates of parameters, detailed in tables 5 and 6 , in combined data, i.e. sets $(1+3)=S$ and $(2+4)=L$

(a) Table 5 parameters

\begin{tabular}{|c|c|c|c|}
\hline \multicolumn{2}{|l|}{$\mathrm{S}$} & \multicolumn{2}{|l|}{$\overline{\mathrm{L}}$} \\
\hline 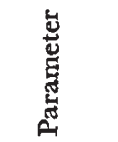 & 葋 & 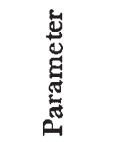 & 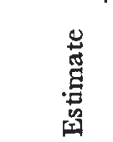 \\
\hline Mean $=$ & $\begin{array}{r}4.1355 \\
\pm 0.0149\end{array}$ & Mean $=$ & $\begin{array}{r}4.6510 \\
\pm 0.0125\end{array}$ \\
\hline $1=$ & $\begin{array}{l}-0.1271 \\
\pm 0.0188\end{array}$ & $1=$ & $\begin{array}{r}0.1104 \\
\pm 0.0170\end{array}$ \\
\hline $2=$ & $\begin{array}{l}-0.1813 \\
\pm 0.0188\end{array}$ & $2=$ & $\begin{array}{r}0.0904 \\
\pm 0.0166\end{array}$ \\
\hline $3=$ & $\begin{array}{r}0.2166 \\
\pm 0.0234\end{array}$ & $3=$ & $\begin{array}{r}0.1225 \\
\pm 0.0210\end{array}$ \\
\hline $5=$ & $\begin{array}{l}-0.0562 \\
\pm 0.0223\end{array}$ & $4=$ & $\begin{array}{r}0.0892 \\
\pm 0.0189\end{array}$ \\
\hline $6=$ & $\begin{array}{r}0.1051 \\
\pm 0.0329\end{array}$ & $15=$ & $\begin{array}{r}0.0552 \\
\pm 0.0197\end{array}$ \\
\hline $7=$ & $\begin{array}{r}0.1050 \\
\pm 0.0306\end{array}$ & & \\
\hline $11=$ & $\begin{array}{r}-0.0440 \\
\pm 0.0147\end{array}$ & & \\
\hline
\end{tabular}

$\chi^{2} \quad 14 \cdot 54$

Probability: $0 \cdot 1-0 \cdot 05$ (b) Table 6 parameters

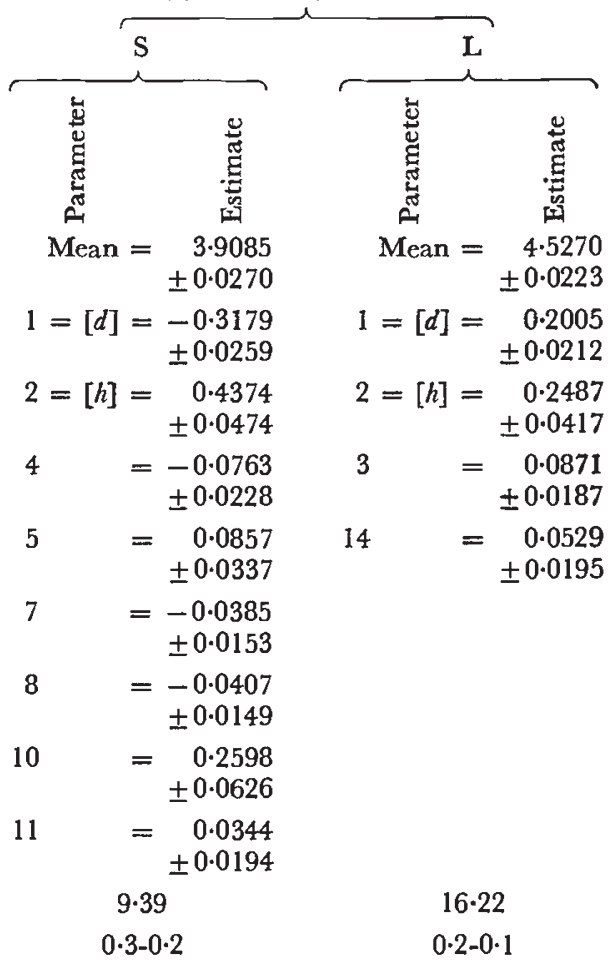

Similar modification of the table 6 group of coefficients allowed prediction from this alternative model. In this case, coefficients for $[h]$ in the design matrix (table 6) were all positive, and all were retained in $X_{8}$ and $X_{1}$; although the two dominance estimates were significantly different, the average value of $[h]$ for $\mathrm{S}$ and $\mathrm{L}$ was employed in $b_{s}$ and $b_{1}$, with $p$, a vector of predictions, being found as above. Comparison of observed with predicted progeny type means was made through Spearman's rank correlation coefficient.

Using parameter estimates $(a)$ in table 8, i.e. estimates derived from application on table 5 type models to combined date, a rank correlation of 0.59 ( $\mathrm{P} 0.02-0.01$ ) between observed set 5 means and those predicted (shown in table 9) was obtained. Using only the parental effects estimates, 
TABLE 9

$\log _{n}$ total plant weight; set 5

(1) $\mathrm{S} \times \mathrm{L}$ observed progeny means

\begin{tabular}{c|cccc|c}
\multicolumn{1}{c}{} & 1 & 2 & 3 & 4 & Means \\
1 & 3.46 & 3.98 & 4.05 & $4 \cdot 46$ & 3.99 \\
2 & $4 \cdot 05$ & $4 \cdot 28$ & $4 \cdot 10$ & $4 \cdot 19$ & $4 \cdot 16$ \\
3 & $4 \cdot 36$ & 3.93 & $4 \cdot 32$ & $4 \cdot 74$ & $4 \cdot 34$ \\
4 & 4.58 & $4 \cdot 71$ & $4 \cdot 22$ & $4 \cdot 79$ & 4.58 \\
\cline { 2 - 5 } Means & $4 \cdot 11$ & 4.23 & $4 \cdot 17$ & 4.55 &
\end{tabular}

(2) $\mathrm{S} \times \mathrm{L}$ predicted progeny means using table 5 model; parameter estimates shown in table $8(a)$

\begin{tabular}{c|cccc|c}
\multicolumn{1}{c}{} & 1 & 2 & 3 & 4 & Means \\
\cline { 2 - 5 } 1 & $4 \cdot 13$ & $4 \cdot 18$ & $4 \cdot 19$ & $4 \cdot 30$ & $4 \cdot 20$ \\
2 & $4 \cdot 08$ & $4 \cdot 32$ & $4 \cdot 22$ & $4 \cdot 35$ & $4 \cdot 24$ \\
4 & $4 \cdot 17$ & $4 \cdot 31$ & $4 \cdot 41$ & $4 \cdot 44$ & $4 \cdot 33$ \\
4 & $4 \cdot 27$ & $4 \cdot 32$ & $4 \cdot 53$ & $4 \cdot 64$ & $4 \cdot 44$ \\
\cline { 2 - 4 } Means & $4 \cdot 16$ & $4 \cdot 23$ & $4 \cdot 34$ & $4 \cdot 43$ &
\end{tabular}

plus their interaction, from table $8(a)$ in the calculations yielded a vector $p$ whose elements showed a slightly higher correlation of $0.64(\mathrm{P}<0.01)$ with observed means. Estimates and effects other than parental plus interaction thus apparently contributed nothing to prediction of the actual $\mathrm{S} \times \mathrm{L}$ progeny type means. Some doubt might, therefore, exist about the ability to extrapolate using estimates of cytoplasmic effects from combined data.

In the case of parameter estimates $(b)$ from table 8 , i.e. estimates derived from table 6 type models, rank correlations were not significant either when all the estimates were employed to obtain $p$, or when $d$ and $h$ only were used.

\section{Disqussion}

Information about the segregational and recombinational properties of nuclear genes has provided an immediate basis for models describing inheritance in genetical experiments with quantitative characters in higher plants. Lack of information about the mechanism involved in cytoplasmic inheritance has inhibited a similar modelling approach in its case.

Barnes (1968) found that all progeny of $F_{1}$ 's as females were superior; this superiority was reflected in the highly significant component associated with the $F_{1}$ maternal effect in the appropriate model summarising his data from an identical experimental arrangement of crosses to that described here. Results from sets 3, 4 and 5 here paralleled Barnes' findings, in that differences were detected between the means of $F_{1}$ and of $P_{1}, P_{2}$ progeny, either in a maternal or paternal direction. However, in only one case (set 4, paternal) was the difference in favour of the $F_{1}$; in this respect the findings here differed from those of Barnes.

The analyses here have been concerned with means, and more particularly with cytoplasmic effects revealed by these means. As well as testing $F_{1}$ reciprocal differences in the five sets of crosses made between the two genotrophs and two genotypes, cytoplasmic effects within and across segregating generations were examined. Across $B_{1}, B_{2}$ and $F_{2}$ generations 
it was possible to demonstrate that cytoplasmic effects stemming from the alternative $F_{1}$ 's were present, and that these effects could be transmitted through the male or female gametes. Simple models developed from the analysis of row and column effects in a data matrix supplied the basis for this demonstration, as well as the further extraction of S and L's effects over both genotypes with which they were each crossed. In this part of the analyses of the five sets of crosses, the results paralleled the findings of Durrant (1965) in a diallel cross between two flax genotrophs ( $L$ and S) and four flax genotypes. Using $\mathrm{F}_{2}$ family variance (log data) from this diallel, an analysis of reciprocal differences was developed by Durrant to examine cytoplasmic effects on homozygotes' and heterozygotes' behaviour. S showed greater dominance in progeny resulting from its use as a male parent, compared to its use as a female, while $L$ exhibited a general increment in its female array compared to its male. Thus, cytoplasmic as well as nuclear changes appeared to have been induced by environmental treatments. In addition, there were distinct differences in the transmission of these changes through the male and female gametes of the two genotrophs.

While cytoplasmic effects were demonstrably present in the two genotrophs, their explanation could not, of course, be deduced from these data. Essentially, male and female gametes of a given genotroph must have received differential cytoplasmic contributions during their formation. Several suggestions might be made concerning such differential contributions; chloroplast or mitochondrial DNA, long-lived messenger RNA, indole acetic acid (IAA) level coupled with specific thresholds for particular genes in their response to switching on for RNA synthesis by IAA, or different arrays of isoenzymes of peroxidase, an enzyme concerned in controlling IAA level in plant tissues, could be involved. It would be technically feasible to attack some of these possibilities with appropriate procedures. Pursuit of an explanation for these cytoplasmic effects could well require utilisation of a wide range of techniques, but the fact that no immediate differences between reciprocal $F_{1}$ hybrids were detected in the data here emphasised the interrelationship which must exist between any differential cytoplasmic contributions and nuclear genes.

Acknowledgments. - Thanks are extended to Dr Alan Durrant for help and comments during both the experimental phase of the work and the preparation of this manuscript. Thanks are also extended to my colleague Dr Kurt Sittmann for valuable discussions during the analyses of these data, and to $\mathrm{Dr}$ V. M. Seshadri of the Mathematics Department, McGill University, for comments on certain aspects of the weighted least-squares procedure. The work reported here was supported in part by the National Research Council of Canada and the Agricultural Research Council of Britain.

\section{REFERENCES}

BARNES, R. W. 1968. Maternal control of heterosis for yield in Drosophila melanogaster. Heredity, 23, 563-572.

DURRANT, A. 1962a. Induction, reversion and epitrophism of flax genotrophs. Nature, $196,1302-1304$.

DURRANT, A. 1962b. The environment induction of heritable change in Linum. Heredity, $17,27-61$.

DURRANT, A. 1965. Analysis of reciprocal differences in diallel crosses. Heredity, 20, 573-607.

DURRANT, A. 1971. Induction and growth of flax genotrophs. Heredity, 27, 277-298. 
DURRANT, A., AND TYSON, H. 1964. A diallel cross of genotypes and genotrophs of Linum. Heredity, 19, 207-227.

EVANS, G. M., DURRANT, A., AND REes, H. 1966. Associated nuclear changes in the induction of Flax genotrophs. Nature, 212, 697-699.

EVANS, G. M. 1968a. Nuclear changes in Flax. Heredity, 23, 25-38.

EVANs, G. M. 1968b. Induced chromosomal changes in Linum. Heredity, 23, 301-310. MATHER, K., AND JiNKs, J. L. 1971. Biometrical Genetics. Cornell University Press. 